\section{A enurese em crianças e seus significados para suas famílias: abordagem qualitativa sobre uma intervenção profissional em saúde}

\section{Child enuresis and parental meanings: a qualitative perspective for healthcare professionals}

Ana Helena Rotta Soares 1

Martha Cristina Nunes Moreira 2

Lúcia Maria Costa Monteiro 3

Eliane Maria Garcez de Oliveira Fonseca 4

1,2 Programa Saúde e Brincar. Instituto Fernandes Figueira. Fundação Oswaldo Cruz. Avenida Rui Barbosa, 716, 50 andar. Flamengo. Rio de Janeiro, RJ, Brasil. CEP: 22.250-020

3,4 Ambulatório de Urodinâmica Pediátrica. Instituto Fernandes Figueira. Fundação Oswaldo Cruz.

Rio de Janeiro, RJ, Brasil

\begin{abstract}
Objectives: to discuss perception and meanings by families to child related enuresis through a social and anthropological perspective in the context of issues identified in the explanatory models of disease.

Methods: experience report, based on semi-structured interviews performed with twenty four (24) families/caretakers of children with enuresis.

Results: families of patients with enuresis expressed the need of defining the disease in a subjective manner, attempting to understand it through the feelings that it unleashes, of the changes in behavior and effects caused in other people by this disease. It was determined that enuresis is grouped in two overlapping fields: the one holding the child responsible for his or her enuresis and external factors such as the family environment and economic and social situation.

Conclusions: it is recommended that healthcare professionals be aware of the risk of the biomedical regulation of their speech for it interferes with the understanding and the development of adequate treatment. Healthcare professionals should be informed on the possibility of child abuse related to enuresis and the discussion of possible strategies when working with this type of patient.
\end{abstract}

Key words Enuresis, Stereotyping, Perceptiv

\section{Resumo}

Objetivos: discutir as percepções e significados atribuídos pelas famílias acerca da enurese vivida por seus filhos, através de uma perspectiva socioantropológica que problematiza as mesmas no contexto das questões identificadas no interior do campo dos modelos explicativos da doença.

Métodos: relato de experiência, baseado em entrevistas semi-estruturadas, realizadas junto a 24 (vinte e quatro) familiares/cuidadores de crianças com quadros de enurese.

Resultados: as famílias de pacientes com enurese demonstram a necessidade de definir a doença de maneira subjetiva, entendendo-a através dos sentimentos que a mesma desencadeia, das mudanças comportamentais e das diferenças encontradas no relacionamento com as outras pessoas devido à mesma. Observa-se que os significados da enurese se organizam em dois campos que se cruzam: a responsabilização da própria criança por sua enurese e os fatores externos, como o ambiente familiar e a situação econômica e social.

Conclusões: recomenda-se que profissionais de saúde estejam atentos aos perigos da normatividade biomédica de seu discurso, já que o mesmo dificulta a compreensão e elaboração dos tratamentos necessários. Profissionais de saúde devem estar informados sobre o risco de maus-tratos relacionados à enurese, o que justifica a discussão acerca de possíveis estratégias de enfretamento dessa realidade na ação profissional junto a essa clientela.

Palavras-chave Enurese, Estigmatização, Percepção 


\section{Introdução}

Este artigo se caracteriza por ser um relato de experiência, baseado em entrevistas realizadas junto aos familiares/cuidadores de crianças com quadros de enurese atendidos no Ambulatório de Urodinâmica do Instituto Fernandes Figueira da Fundação Oswaldo Cruz (FIOCRUZ). Tais entrevistas visaram atender a demanda da equipe médica e de enfermagem em melhor compreender quais os fatores intervenientes nos quadros de enurese apresentados por crianças atendidas no serviço, e que não estavam referidos somente a alterações de ordem fisiológica. Ainda, essas entrevistas geraram dados para a pesquisa "Análise de Fatores Indicadores de Disfunção Miccional em Crianças e Adolescentes Enuréticos",1 desenvolvida no interior do grupo "Avanços em Uropediatria", que visava, entre outras questões, explorar os entrelaces de fatores fisiológicos e psicossociais da enurese. Tal perspectiva se encontra consoante com a visão dos profissionais desse serviço, que procuram atender não só aos problemas clínicos da clientela, mas, também, aos problemas psicossociais que se revelam em virtude da doença ou que possivelmente são responsáveis pelo agravamento da mesma.

O presente estudo tem como objetivo apontar os diferentes significados da enurese em famílias de crianças portadoras da doença a fim de discutir recomendações para abordagens dos pacientes e famílias em referência por profissionais de saúde.

\section{A enurese: uma visão além da fisiologia}

A palavra enurese vem do grego enourein que significa fazer urina ou urinar. A enurese infantil é então definida como uma disfunção miccional que se caracteriza pela perda de urina involuntária durante uma idade em que a criança já deveria ter obtido controle.

A literatura internacional tem atribuído grande atenção ao estado emocional de crianças com enurese. Hagglaof et al.,2 em trabalho sobre estima pessoal e crianças com enurese, afirmaram que, anterior ao tratamento, crianças enuréticas demonstraram baixa auto-estima quando comparadas com um grupo de controle. Após seis meses de tratamento psicológico, as mesmas demonstraram um nível de auto-estima compatível com o grupo de controle. Em 1987, Moffatt et al. ${ }^{3}$ observaram a mudança de atitudes e comportamento de crianças com enurese, após terapia de condicionamento. Os pesquisadores dividiram 121 crianças em dois grupos. O primeiro grupo recebeu durante três meses uma terapia de condicionamento, já o segundo grupo aguardou o tratamento durante esses três meses. Os resultados demonstraram uma melhora na imagem pessoal em crianças após o término ou a redução da enurese noturna devido à terapia.

O impacto da enurese na vida da criança portadora não se limita a ela própria; as famílias afetadas pela doença sofrem consequências muitas vezes devastadoras. Para os pais e cuidadores dessas crianças, a enurese é uma das mais frustrantes disfunções da infância. Entre os fatores de estresse familiar encontram-se a elevação de despesas, tempo, e esforços associados com a limpeza e compra de novas roupas pessoais e roupas de cama, bem como colchões, travesseiros e sofás. Warzak 4 descreveu, a partir de uma revisão da literatura existente relacionada ao tema enurese na infância, as principais implicações psíquicas vividas por crianças e adolescentes com enurese noturna. Entre as consequências negativas da enurese encontram-se a baixa estima pessoal, o isolamento, e o alto estresse relacionado ao medo de ser ridicularizado por companheiros. Esse autor também adverte acerca do alto risco violência física e emocional, principalmente quando a criança é percebida pela família como preguiçosa, relutante ou rebelde.

Em 1990, Devlin e O'Cathalin5 estudaram crianças com enurese referidas a uma clínica comunitária com o propósito de apontar fatores de risco para o tratamento das mesmas. Durante a consulta médica as crianças e seus familiares foram entrevistadas para abordar seu histórico médico-psiquiátrico e estresse familiar. Os resultados trabalhados evidenciaram que distúrbios psiquiátricos, estresse familiar, e grau de preocupação demonstrado pela criança eram os mais importantes fatores de prognóstico para o tratamento.

A revisão acima nos auxilia no argumento de que a enurese é um distúrbio que pode desencadear situações de constrangimento, estresse, comprometimento na auto-estima e, portanto, na saúde global de crianças que a vivenciam. Pode-se ainda compreender que, nesse campo, o lugar ocupado pela família como um suporte para o tratamento e acolhimento dessa criança só poderá ser bem vivenciado caso o profissional de saúde consiga perceber os fatores intervenientes no quadro de enurese, os modelos explicativos e estratégias que essa mesma família elabora para lidar com esse transtorno. Assim, o presente trabalho tem como propósito analisar as percepções e significados familiares sobre a enurese, bem como descrever a experiência familiar das crianças enuréticas tratadas no Instituto 
Fernandes Figueira da Fundação Oswaldo Cruz, a fim de proporcionar uma reflexão sobre as estratégias de abordagem profissional na atenção à saúde dessas crianças portadoras de enurese e suas famílias.

\section{A experiência do adoecimento e seus significados}

Tanto para Kleinman 6 quanto para Good 7 as alterações ligadas à doença são interpretadas pelo doente, sua família e seu médico. Essa visão da antropologia médica ressalta a importância de se perceber a saúde através de uma perspectiva cultural, ou seja, aquela que se refere às inúmeras interpretações, formuladas dentro do campo da saúde, por diferentes povos. Assim, a disciplina aborda a doença através de um processo tanto subjetivo, quanto coletivo, englobando valores, regras, crenças e expectativas.

Sendo assim, a doença e a experiência que a mesma acarreta se configuram através de um processo semântico multidimensional, construído a partir do encontro dos universos biológico, psicossocial e cultural. Dentro dessa perspectiva, percebe-se a distinção entre a doença como experiência e a doença como processo. Helman 8 utiliza o termo illness para referir-se à experiência da doença e aos sentimentos de adoecimento. Na visão do autor, a doença não é apenas resposta individual do paciente ao seu mal-estar, ela é construída também através das interações sociais do mesmo, bem como de suas questões psíquicas e morais, e o contexto cultural no qual ele se insere. A experiência de viver com a doença ultrapassa a dimensão física e permite a construção de significados para sua enfermidade. Já o termo disease, corresponde ao paradigma científico da medicina moderna, referindo-se às mudanças e anomalias na função ou estrutura dos orgãos ou sistemas. Sendo assim, Eisenberg (1977: 9)9 afirma,"... pacientes sofrem de illnesses; médicos diagnosticam e tratram diseases" Ainda, é importante ressaltar que segundo o mesmo autor, os conceitos acima citados não obedecem a uma relação de valor equivalente no que se refere à experiência de adoecimento. Ou seja, a illness pode acontecer sem a presença, da disease e vice-versa. Além disso, os dois paradigmas nem sempre seguem níveis compatíveis de intensidade. Como explicado por Eisenberg, ${ }^{9}$ um paciente portador de hipertensão que não apresenta sintomas pode hesitar em seguir o tratamento indicado por seu médico, já que o mesmo o faz sentir-se "doente". Nesse caso, o que levará o paciente a aderir ao tratamento será o agravo de seu quadro, que o levará a sentir-se realmente um paciente e a concordar com seu médico que está doente e precisa de tratamento.

Seguindo a mesma perspectiva, Adam e Herzlich ${ }^{10}$ ressaltam que além das influências culturais e subjetivas da expressão e visão de sintomas, podemos observar também a configuração social da doença, ou seja, o que é considerado como doença em cada sociedade. Dentro dessa noção, fenômenos tidos pela medicina como patológicos não são considerados como sintomas pela população em geral. Os autores apontam como exemplo desse aspecto da modelação cultural, certos grupos étnicos que acreditam que os vermes intestinais fazem parte do processo de digestão e assim são necessários para o funcionamento do indivíduo.

No sentido de compreender e estudar os traços cognitivos e de comunicação entre profissionais de saúde e pacientes, Kleinman 11 desenvolveu o conceito de modelo explicativo da doença. Segundo o autor, o construto pode ser definido como:

"... o conjunto de idéias de todos os envolvidos no processo clínico sobre um episódio de doença e seu tratamento"

(Kleinman 1980; apud Helman; 1994:

107). 11

Além disso, os modelos tendem a gerar explicações sobre a etiologia da doença, a maneira e momento de seu surgimento, seus processos patofisiológicos, seu curso e nível de severidade, e finalmente, os tratamentos apropriados. Sendo assim, os modelos se referem a um episódio específico, e apesar de serem altamente influenciados pela cultura, valores e crenças da sociedade onde o indivíduo adoecido se encontra inserido, não são idênticos a generalizações da mesma sociedade. Tais modelos explicativos são gerados tanto por pacientes como por profissionais de saúde e se configuram como conjuntos de generalizações e significados com o fim de administrar um episódio ou situação de enfermidade. No caso de modelos leigos, os mesmos são fortemente influenciados por questões subjetivas e de personalidade. Já no caso de modelos gerados por profissionais de saúde, esses se referem, primordialmente, à lógica da ciência médica e não a fatores sócio-culturais do paciente. ${ }^{6}$ Assim, surge a necessidade de gerar abordagens em saúde que englobem tanto a cultura quanto os fenômenos orgânicos vividos por pacientes adoecidos.

A compreensão do comportamento de uma população frente a seus problemas de saúde, ou seja, a maneira como indivíduos significam e comunicam seus males, bem como a maneira que os mesmos traçam o percurso das intervenções aceitáveis, são 
elementos essenciais para a formulação de ações em saúde. Os modelos utilizados para exprimir as mudanças e anomalias fisiológicas e corporais se constroem através dos encontros dos significados e leituras técnicas, com as apreensões do próprio paciente e sua família.

\section{Métodos}

Durante as discussões para situar a metodologia mais adequada para os sujeitos do estudo em referência, famílias de crianças portadoras de enurese, foi observado que duas questões eram de extrema importância. Primeiro, a metodologia deveria funcionar como facilitador no contato com os sujeitos, e segundo, essa metodologia deveria ter a habilidade de fazer "falar o objeto". Ou seja, a metodologia deveria não só facilitar a expressão dos valores, crenças e expectativas dos sujeitos, mas também criar um espaço para que os mesmos viessem a se sentir à vontade para expressar suas experiências.

Tendo em conta que o presente estudo pretende explorar e compreender a experiência e os significados da enurese infantil em famílias a partir de suas interações com uma série de crenças e valores sociais e familiares, empregamos uma abordagem qualitativa na execução da presente investigação. 12

Adicionalmente, existe a preocupação que essa pesquisa seja representativa da real experiência vivida por essas famílias. Sendo a pesquisa qualitativa um método descritivo, ela poderá expor as questões estudadas mais detalhadamente, e conseqüentemente aprofundar-se com mais sucesso nas interações entre a criança adoecida, sua família e o contexto social no qual estão inseridos, na construção dos significados da enurese como experiência em suas vidas.

No que diz respeito ao momento de produção dos dados, acredita-se na pertinência de buscar técnicas de pesquisa que melhor se adequem aos sujeitos da mesma, isto é famílias de crianças portadoras de enurese.

Foram realizadas entrevistas semi-estruturadas, as quais não exigem a priori regras precisas a serem seguidas e facilitam o acesso aos sentimentos e dificuldades dos sujeitos, além de permitirem maior profundidade no estabelecimento de uma relação de confiança e amizade entre pesquisador-pesquisado. ${ }^{13}$ Essa relação propicia, então, o surgimento de outros dados. Desse modo, essa técnica nos permitiu ambientar-nos com a realidade das famílias de portadores de enurese, além de estabelecer um rapport com as mesmas. É importante frisar que o momento das entrevistas foi de grande importância para as famílias dos pacientes, já que para muitos, esta foi a primeira oportunidade de expressar abertamente seus sentimentos sobre os significados e características da doença de seus filhos. Percebeu-se, ainda, que a disponibilidade de uma outra abordagem em relação à doença de seus filhos, provocou, em algumas das pessoas entrevistadas, uma demanda por um espaço no qual pudessem compartilhar suas experiências, valorizando essa abordagem como algo que possibilita expressar outras preocupações que não somente aquelas referidas diretamente às prescrições medicamentosas e exames.

O roteiro das entrevistas foi construído com o propósito de permitir o acesso às dimensões discursivas nas quais estão embutidos fatores emocionais, da saúde física, familiares e ambientais na experiência da enurese em crianças e suas famílias. Contudo, tal roteiro sofreu modificações de acordo com o curso da discussão levantada por entrevistados, ou seja, o roteiro serviu como um instrumento norteador da experiência da enurese em famílias (Quadro I). O roteiro não incluiu perguntas relacionadas às variáreis econômicas, sócio-culturais ou referências sócio-demográficas. A pergunta de número 3 do roteiro de entrevistas é a única que permite o acesso a dados referentes à dinâmica familiar, que a princípio permitem, inclusive, um posicionamento mais subjetivo e discursivo dos sujeitos. Isso porque em um único encontro perguntas mais abertas e que focalizam aspectos da dinâmica familiar, da história, vivência e administração da doença funcionam como facilitadores para a aproximação com as pessoas entrevistadas. Podese considerar que essas entrevistas se inserem no interior das discussões sobre a humanização da atenção à saúde em uropediatria, e contribuem, por seu caráter exploratório, para uma aproximação das dificuldades enfrentadas por essas famílias e suas percepções sobre a enurese de seus filhos. Ainda que pontualmente, a realização das entrevistas permitiu o acesso à experiência vivida por estas crianças a partir dos discursos de seus responsáveis. Ressaltamos que esse exercício pode contribuir para a exposição dos problemas apresentados e o aprofundamento das relações entre o estado emocional das crianças e sua realidade familiar, subsidiando seu tratamento de saúde delas.

O presente trabalho teve como campo o Ambulatório de Urodinâmica do Instituto Fernandes Figueira da Fundação Oswaldo Cruz. Essa Instituição é uma unidade de referência para crianças com quadro de disfunção miccional, que necessitam 
de avaliações em urodinâmica. A avaliação consiste na introdução de uma sonda na uretra do paciente, seguida de enchimento vesical, com o objetivo de avaliar o processo de micção. Tal avaliação estuda a coordenação entre a bexiga, a uretra e o complexo esfincteriano e a integração entre as fases de enchimento e esvaziamento vesical. Segundo a Sociedade Internacional de Incontinência Urinária, a avaliação urodinâmica é definida como o estudo da morfologia, fisiologia, bioquímica e hidrodinâmica do transporte urinário. ${ }^{14}$ Tal estudo está indicado, dentre diversos quadros, para pacientes com enurese. Cabe ressaltar que mesmo sendo um exame invasivo, que provoca reações emocionais de recusa ou desconforto, nesse serviço tal exame só é realizado com o consentimento da própria criança, com o esclarecimento de seus responsáveis, contando ainda com estratégias lúdicas na apresentação do exame à criança. Isso é, durante a recepção de crianças e suas famílias no Ambulatório, bonecas e materiais relacionados ao exame são entregues aos mesmos e o profissional de Psicologia explica o procedimento do exame. Logo depois as crianças podem efetuar o exame nas bonecas, fazer perguntas ou apenas brincar com os materiais oferecidos.

Foram realizadas 24 entrevistas, agendadas previamente por telegrama, com os responsáveis de crianças enuréticas atendidas no Ambulatório de Urodinâmica. As entrevistas aconteceram durante o tratamento das crianças no acima citado ambulatório. Dentre os entrevistados, 13 eram mães; seis, avós; três, pais; e, duas, tias. No caso das duas tias entrevistadas, os dados não foram utilizados já que as acompanhantes desconheciam informações essenciais sobre a criança e não tinham uma convivência diária ou uma participação ativa nos cuidados da mesma. Além desses aspectos, as mesmas não tiveram nenhuma fala significativa com relação a história das crianças e seus processos de adoecimento e apenas estavam acompanhando as crianças ao hospital naquele dia específico.

Ainda, ao entrarem para a sala de entrevista, as crianças e seus responsáveis escutavam uma breve apresentação do "por quê" do convite para participarem da entrevista, e a criança posteriormente era convidada a compartilhar um espaço lúdico existente na Instituição e coordenado pelo "Saúde e Brincar", "Programa de Atenção Integral à Criança Hospitalizada" que atende a crianças, adolescentes e seus acompanhantes, com a proposta interdisciplinar de utilização do lúdico como forma de intervenção terapêutica, visando prevenir agravos a quadros de hospitalização e de convivência com tratamentos ambulatoriais recorrentes. Assim, somente familiares
Quadro 1

Roteiro das entrevistas.

1. Como era sua vida antes antes de seu filho nascer?

2. Como era sua vida quando seu filho começou a apresentar esses problemas?

3. Qual é a sua situação familiar agora? Quem mora em sua casa?

4. Porque você acha que seu filho tem esse problema?

5. Como é encarado esse problema na sua família?

6. Quem sabe sobre esse problema?

7. Como você ajuda o seu filho a dar conta do problema? Exemplos: acordar durante a noite, usar alarmes, conversar sobre o problema e recompensas por não fazer xixi na cama.

8. O que você acha que seu filho poderia fazer para melhorar?

9. Você vê limites dessa doença para seu filho?

10. Como você vê seu filho no futuro (em casa, na escola, com amigos, profissionalmente)?

foram entrevistados.

Do processo de análise dos dados, fez parte um primeiro momento no qual as entrevistas foram transcritas procedendo-se à leitura integral e exaustiva dos discursos, buscando apreender seu sentido global, estruturas relevantes, e noções centrais. Após essa etapa, foram organizadas as falas, tendo sido construídas duas categorias empíricas em acordo com as discussões sobre os modelos explicativos da doença apresentados por Helman. ${ }^{8}$ Entende-se que tal operacionalização de interpretação dos dados permitiu ao pesquisador um maior aprofundamento do conteúdo das mensagens encontradas nos discursos dos familiares entrevistados. 15

\section{Resultados}

Os dados demonstraram uma grande diversidade de arranjos familiares dentre os entrevistados. Apesar disso, a organização familiar predominante no discurso dos sujeitos foi o do modelo de família nuclear. Verificou-se que 13 dos entrevistados apresentavam um núcleo familiar tradicional, ou seja, aquele onde a família se constituía por ambos pais e seus filhos, residentes no mesmo domicílio. No entanto, tal núcleo também demonstrou variações, ou seja, dentre os citados, quatro contam com a coabitação de outros familiares como avós, irmãos, cunhados e amigos. Nesses casos, os cuidados com as crianças são compartilhados por todos que ali residem, ou seja, as crianças dessas famílias não são de responsabilidade exclusiva do pai ou da mãe, mas 
também dos avós, tios e amigos que dividem o domicílio. Ainda, 15\%, possuem auxílio da família extensa que reside próximo ao domicílio da família em questão, sendo esse arranjo possível em decorrência da divisão de um terreno entre vários familiares.

Encontraram-se também, em seis das famílias contempladas, organizações familiares onde os avós assumem papéis centrais como cuidadores e provedores das crianças. Tais casos são motivados pelo reconhecimento da mãe e do pai de sua impossibilidade de criar o filho, seja essa por questões econômicas, emocionais ou referentes à idade. Tal situação se constrói a partir do abandono ou doação da criança pelos pais e o acolhimento da mesma pelos avós. Dentre esses casos, quatro das famílias não contam com qualquer auxílio, seja esse financeiro ou afetivo dos pais biológicos. No entanto, dois dos pais ainda residem no mesmo domicílio, apesar de não ocupar o papel de cuidador ou provedor da criança, sendo apenas percebido como um irmão ou irmã mais velha.

Ainda, foi observada uma família monoparental, tendo a mãe como cuidadora e provedora principal. Nesse caso, a organização se deu após o falecimento da avó materna que inicialmente havia assumido integralmente os cuidados da criança.

Dentre os entrevistados, foi verificado que cinco das famílias foram afetadas pelo alcoolismo. Nesses casos, os entrevistados acreditavam que as experiências da criança com o familiar alcoolizado haviam causado ou, de certa maneira, agravado a doença. $\mathrm{O}$ índice de violência doméstica entre os entrevistados foi de $31 \%$. Foi observado também um índice de $36 \%$ de crianças abandonadas ou negligenciadas pelo pai, mãe, ou ambos, e em decorrência recebiam cuidados dos avós ou outro parente próximo. O entendimento acerca da doença para essas famílias envolvia sempre a idéia de que a criança seria insegura ou deprimida devido ao abandono ou violência observada ou experimentada em casa.

No momento que os dados foram reunidos, percebeu-se que os significados da enurese, conforme expressado pelos familiares de crianças portadoras, se organizam em dois grandes campos que ora se encontravam entrelaçados, sendo melhor aprofundados através da construção das duas categorias empíricas. A primeira categoria evidenciada nas falas das famílias é a da responsabilização da própria criança por sua doença. A segunda se refere aos fatores externos como origem da doença, entre eles, o ambiente familiar e a situação econômica e social. É importante mencionar que em alguns casos, tais significados também foram acompanhados pela reprodução ou releitura do discurso médico.

Dentro da categoria da responsabilização da criança, foi observada a significação da doença pelas famílias como uma questão de fraqueza ou vulnerabilidade do paciente, devido a características de sua própria personalidade. Nesses casos, as famílias qualificam a doença como preguiça, desobediência ou até uma provocação da criança. Assim, as crianças são freqüentemente castigadas e as interações positivas entre elas e seus pais ficam comprometidas, como pode ser percebido a partir dos trechos abaixo:

"Não tem muito como eu ajudar, porque ela é sem vergonha. O mal dela é a desobe-

diência. Ela sempre quis fazer o que quer na hora que quer" (Responsável 1).

"Ele é muito levado, chega a ser mal

criado. Ele é muito rebelde" (Responsável

5).

"Eu acho que é deboche dela, já bati mas depois larguei" (Responsável 7).

Os trechos acima atribuem ao comportamento individual da criança as explicações para o fato de a criança não controlar a urina. Verifica-se que as crianças são descritas como malcriadas, levadas, provocativas ou até mesmo debochadas. Explicações centradas na criança, como as descritas acima, colocam a mesma em um lugar extremamente perigoso. A criança, nesse caso, tem total responsabilidade pela doença, bem como absoluto poder de cura. Assim, a doença é entendida como decorrência de forças interiores negativas, desequilíbrio, resistência ou fraqueza, que podem estar sob seu controle. Para esses pais depende da própria criança a escolha de "curar-se" da enurese, pois essa cura é entendida não como algo que foge ao controle da criança e precisa de uma intervenção profissional, mas como uma "pirraça". Dessa forma, a enurese não é entendida como doença, e conseqüentemente nunca é reconhecida pela família como um pedido de ajuda, levando ao não enfrentamento da mesma ou a uma procura tardia de cuidados médicos, bem como um baixo engajamento nos tratamentos ou recomendações profissionais. Tal entendimento pode ainda gerar reações violentas por parte da família como estratégia corretiva, expondo assim a criança à situação de violência e maus-tratos.

Apesar das famílias das crianças estarem cientes de que brigas, castigos e ridicularização não são estratégias adequadas para lidar com problema da perda de urina. Em muitos casos se sentem frustradas e recorrem a essas condutas.

"É difícil eu bato, pego o lençol e esfrego em cima dele... falo que já é um homem... 
pra ver se com vergonha ele para conto pros amigos dele" (Responsável 10).

"Em casa ela não leva espancamento, não leva xingamento... em casa eu chamo ela de porca" (Responsável 4).

Durante as entrevistas podemos observar que a perda de urina, mesmo quando diagnosticada como um sintoma de um problema físico, não é facilmente aceita como uma doença legítima pela família, devido à resistência ou fraqueza moral atribuída ao paciente; ou seja, a criança é responzabilizada pela sua ausência de controle sob a urina. No seguinte trecho podemos observar como uma mãe define um comportamento de irresponsabilidade ou esquecimento como causa da enurese, diferenciando o evento do problema médico já diagnosticado pelo serviço de saúde:

"Elas são sem-vergonha também ... ficam

brincando, brincando e faz xixi na calcinha

... aí não é doença não" (Responsável 4).

A categoria empírica relacionada ao ambiente externo está fortemente ligada à estrutura familiar da criança e suas condições de vida. Durante os depoimentos identificados, em muitas ocasiões os responsáveis pelas crianças acreditavam que a enurese refletia algum problema que dizia respeito a sua habilidade de cuidar da criança, e as pressionavam excessivamente para controlarem a urina. Dessa forma os cuidadores pareciam vivenciar uma incapacidade para assumir os rigores e os sacrifícios necessários para a educação de suas crianças e interpretaram a enurese como o confrontamento de tais inseguranças.

Durante as entrevistas, percebemos em alguns participantes o reconhecimento da doença de seus filhos como uma metáfora para sua desordem familiar, negliglência em relação aos filhos, ou despreparo percebido acerca de sua habilidade para gerenciar uma família "saudável". No seguinte depoimento vemos como uma avó se sente despreparada, e de certa forma, até indisponível para criar a neta:

"Ela diz que eu sou muito velha para ser mãe dela e que ela vai embora ... eu já estou velha e cansada mesmo e não escondo não pra ver se alguém me ajuda. Lá em casa só quem gosta dela sou eu e o avô. O pai dela não gosta dela, já tem outra, ninguém gosta da menina" (Responsável 7).

Em outros casos, a doença pode ser explicada como uma reflexão da difícil situação econômica da família ou da inabilidade da mesma em providenciar uma realidade melhor:

"Ele não aceita a realidade dele. Ele não aceita nossa casa, acha que é tudo velho"

(Responsável 5).

As representações culturais da enurese não excluem a releitura dos diagnósticos médicos por parte da família e tais diagnósticos ou termos técnicos acabam por aparecer associados ao repertório de explicações a que as famílias recorrem:

"A médica disse que isso é porque a bexiga

dela é pequena" (Responsável 18).

"Ele foi diagnosticado com bexiga

neurogênica" (Responsável 13).

Quanto aos tratamentos para a administração e cura da enurese, constatou-se que independentemente dos significados atribuídos à doença, as famílias lançavam mão de variadas estratégias para o enfrentamento da mesma. Tais estratégias englobam tanto cuidados médicos, como a utilização do universo sobrenatural. No que diz respeito a esse universo de significações, associamos a seguinte fala de uma avó que relatou um tratamento baseado em uma simpatia, buscando portanto, um modelo de cura e explicação referido ao universo das crenças religiosas:

"Já me ensinaram até uma simpatia...

acender um fogo e quando a brasa tiver bem

acesa mandar ela fazer xixi ..." (Responsá-

vel 4).

No caso dos discursos anteriores, o gerenciamento familiar da doença se dá através de intervenções medicamentosas, recomendações médicas e consultas com o serviço de saúde que aparentemente podem vir a reduzir a angústia da família frente à doença, contribuindo para um ambiente propício para a redução significativa dos sintomas ou a possibilidade de cura. No entanto, a reprodução do discurso médico pela família, como uma cópia de prescrição, parece prejudicar um entendimento mais global da doença, e ao mesmo tempo não contribui para o engajamento em um tratamento.

"Eu acho que tem o problema da bexiga e que se agravou mais com o problema dela com a mãe ... a mãe abandonou a família e tem um outro marido" (Responsável 2).

"Acho que ela tem problema dos nervos e

a doutora disse que ela tem a bexiga

pequena" (Responsável 11).

Finalmente, os discursos indicam o reconhecimento de estratégias práticas de administração da enurese noturna no interior das famílias, como a redução de ingestão de líquidos próximo do horário de dormir da criança e acordar a mesma durante a noite. Apesar do reconhecimento de que acordar a criança durante a noite evita a perda de urina, muitos entrevistados não recorrem a essa estratégia devido à 
necessidade de descansar para estar disposto para o trabalho no dia seguinte. Estratégias como o uso de relógios despertadores não foram consideradas pelos entrevistados como uma possibilidade, já que as crianças tem dificuldade em ouvir o relógio devido ao sono:

"Eu faço o que a doutora mandou, não deixo beber água antes de dormir e acordo durante a noite" (Responsável 6).

"Não dá pra ficar acordando ele se não eu também não durmo e eu trabalho e ainda tenho que acordar cinco horas pra lavar os lençóis" (Responsável 14).

Sobre o futuro vislumbrado para a criança, abordado na última questão do roteiro de entrevistas, os resultados demonstraram que apesar dos problemas enfrentados pelos filhos, seus cuidadores não expressam ansiedade alguma em relação ao futuro dos mesmos. As perguntas que abordavam o tema do desempenho futuro das crianças, em todas as ocasiões receberam respostas que não expressavam um comprometimento dos projetos futuros da mesma. Responsáveis de crianças com um histórico familiar da doença mencionado durante a entrevista, demonstraram certeza que o problema gradativamente se resolveria e que a criança poderia levar uma vida sem complicações.

\section{Discussão}

A seguir contemplam-se os resultados coletados nos discursos dos familiares acerca da enurese vivida por seus filhos, problematizando os mesmos no contexto das dificuldades identificadas no interior do campo dos modelos explicativos da doença. Quais sejam, essas questões ao nosso ver e a partir da perspectiva sócio-antropológica que subsidia este artigo, estão remetidas a um âmbito que ultrapassa os limites do corpo físico, ganhando significados pelas pessoas que compartilham as experiências do adoecimento.

A enurese é um dos mais frustrantes distúrbios infantis. Além dos possíveis problemas psíquicos gerados a partir do distúrbio, percebemos que a família é obrigada a renegociar os espaços e funções familiares a partir do impacto econômico da doença e do aumento de tempo e esforços necessários para os cuidados com a criança.

As categorias que emergiram dos discursos dos familiares entrevistados indicam, principalmente, um grande desejo em descrever e definir a doença de maneira subjetiva, isso é, entender a doença através dos sentimentos que a mesma desencadeia, das mudanças que afetam seu comportamento e das diferenças encontradas no relacionamento com as outras pessoas devido à mesma. Ainda, reconhecemos nos depoimentos a necessidade e a importância de um maior conhecimento do impacto psicossocial da doença e de que essa seja abordada, em sua integralidade, por profissionais, ou seja, que se compreenda o paciente adoecido em todos os lugares da sua vida social. 10

No primeiro campo de significados sobre a experiência da enurese, encontra-se a noção da criança adoecida como total responsável pela doença e conseqüentemente, pela sua cura. Em tais casos, a enurese não é percebida como um distúrbio orgânico, mas como a exteriorização de características negativas da personalidade da criança, entre elas, o desequilíbrio, a fraqueza, e a rebeldia. Essa categoria se apresenta também como um importante fator desencadeante de violência contra a criança portadora da enurese. Nesses casos, a punição física, castigos e humilhações se apresentam como instrumentos de educação e orientação dos filhos enuréticos, vistos como debochados e rebeldes.

No segundo campo de significados encontrados nos discursos dos responsáveis das crianças enuréticas, foram observados significados fundamentados em fatores externos à criança e ao seu corpo, ou seja, o ambiente familiar e/ou a situação econômica e social. A enurese, então, se configura como um sintoma, não de uma patologia médica, mas um reflexo ou metáfora das dificuldades encontradas pelo indivíduo ao longo de sua vida.

Consoante com os resultados de Warzak, 4 que demonstrou que famílias com dificuldades econômicas, sociais ou emocionais se encontram em alto risco para abuso físico e emocional, observouse, na presente pesquisa, que as questões relacionadas às dificuldades sociais, emocionais e financeiras das famílias nas quais estas crianças se encontravam influenciou, tanto a maneira como a doença era significada, quanto administrada. Ainda, em conformidade com os resultados do mesmo autor, a presente pesquisa também indica que as crianças com enurese são afetadas por consequências psicossociais negativas devido ao impacto da doença na vida de seus familiares. Ou seja, irmãos de crianças com enurese podem se sentir envergonhados ou limitados devido ao problema do irmão, além de sentirem-se ameaçados pela possível revelação do problema para amigos.

Ainda sobre os fatores externos à criança, segundo Helman, 8 até doenças graves e de risco como o câncer ou a AIDS, freqüentemente possuem uma explicação marcada pela imaginação popular e 
pelas crenças sobre a moral, a saúde e o sofrimento humano. Essas doenças passam a ser muito mais do que um simples conjunto de sintomas ou um processo de adoecimento, se tornando metáforas para algum mal ou perigo da vida cotidiana, ou até mesmo uma metáfora para um comportamento social ou familiar percebido como imoral ou negligente.

No interior dessas discussões sobre a representação cultural da enurese, percebemos modelos explicativos baseados no que Helman chama de "mundo sobrenatural". Aqui o doente ou seus familiares explicam a doença a partir de entidades sobrenaturais "... preces e arrependimento, não penicilina, curam o pecado" (Helman; 1994: 121). ${ }^{8}$

É importante que o profissional de saúde entenda que, apesar de a criança não necessariamente se beneficiar com essa prática, a família se sente mais ativa no tratamento dela e se apropria com mais facilidade da doença quando tem liberdade para expressar seu universo de crenças e valores. Nesse sentido, tais estratégias não devem ser rejeitadas pelos profissionais de saúde logo na primeira abordagem. Porém, é importante que tais práticas nunca sejam substituídas pelo tratamento médico, mas sirvam de ferramenta para aumentar o engajamento familiar no tratamento. É necessário ressaltar, portanto, a necessidade de uma negociação por parte do médico que tente adequar crenças e práticas populares, propiciando o empowerment das famílias no tratamento proposto, através da utilização de recursos próprios do paciente e sua família para produzir comportamentos saudáveis e exercitar seus conhecimentos.

Foram identificadas, ainda nesse campo de significados, explicações baseadas em localizações corporais para significar o mal-estar. Tais explicações vão ao encontro das discussões de Helman, ${ }^{8}$ nas quais o autor descreve o universo do paciente como um dos possíveis locais de representação das teorias leigas que situam a etiologia dos problemas de saúde. Essas teorias são baseadas em crenças relacionadas à estrutura, funcionamento e mau funcionamento do corpo, e, apesar de serem fundamentadas em premissas científicas incorretas, podem propiciar a elaboração do paciente em relação à doença. No entanto, explicações centradas no paciente podem gerar um processo de culpabilização da criança, já que a responsabilidade da doença recai sobre a mesma. Aqui, a criança e seu corpo são responsabilizados pela doença devido a algum comportamento incorreto, debilidade corporal ou de caráter, ou um desequilíbrio. Esse modelo explicativo não permite que a vivência da doença seja dividida pela criança com outros fatores, como o funcionamento da família. É importante ressaltar que explicações médicas quando muito localizadas no corpo, podem reforçar a visão de culpabilização da criança; por isso é importante que o profissional encare a doença como multifatorial e que essa visão esteja presente em seu discurso.

\section{Recomendações para o atendimento de saúde:}

A vivência familiar da enurese pode em muitos casos agravar os sintomas da doença ou gerar problemas relacionados ao reconhecimento das dificuldades da criança, Devido a essas dificuldades, parece ser importante que os profissionais de saúde compreendam o papel dos valores de referência das famílias na convivência com a enurese de seus filhos e identifiquem as estratégias de compreensão do papel que esse distúrbio ocupa nesse universo.

Além de investigar a enfermidade, cabe ao médico apreender os significados e origens atribuídas à mesma pelos pacientes e seus familiares.

Os autores deste trabalho consideram relevante que o serviço de saúde valorize, através de seus profissionais, a discussão do modelo explicativo do paciente e sua família. Através dessa valorização, o profissional de saúde pode junto ao usuário trabalhar preconceitos pessoais ou distorções sócio-culturais em relação à doença, ganhando um novo sentido o tratamento prescrito pelo médico, e conseqüentemente, elevando o engajamento no mesmo. Compreendendo o tratamento da enurese como um processo complexo, multifacetado e permeado por valores e dificuldades, os profissionais de saúde podem qualificar esse tratamento com a perspectiva do acolhimento. Helman 8 aponta que o tratamento médico nunca deve ser apenas direcionado para disfunções físicas; durante a consulta o profissional deve procurar considerar as questões relacionadas às facetas emocionais, sociais, culturais e religiosas, que certamente serão em algum momento identificadas como fortes intervenientes no processo de adoecimento.

Nas interpretações das famílias acerca da enurese de suas crianças, foi identificado que os significados atribuídos à mesma se organizam em dois grandes campos que se cruzam: um remetido ao terreno da responsabilização da própria criança por sua enurese, seja por uma "pirraça ou resposta malcriada", ou ainda por uma debilidade física, e outro remetido a fatores externos, como o ambiente familiar e a situação econômica e social. Como foi mencionado anteriormente, profissionais devem reconhecer os significados atribuídos à doença e 
decodificá-los, bem como ajudar pacientes e seus familiares a construir um entendimento mais completo das causas e das possibilidades do tratamento da enurese.

É importante também que os profissionais de saúde estejam informados sobre o risco de maus tratos no interior das famílias de crianças com enurese. Durante as visitas clínicas os profissionais devem ficar atentos a questões relacionadas à realidade sócio-familiar dessas crianças e procurar saber como a família lida com as questões relacionadas à doença. As famílias devem ser informadas de que crianças usualmente não perdem urina por preguiça ou para desafiar os pais e que castigos físicos, ridicularização e humilhações não são estratégias ideais para lidar com a doença, e podem, inclusive, intensificar os sintomas da mesma, além de ocasionar uma baixa estima, ansiedade e outros sentimentos de auto-desvalorização.

Percebemos que o discurso médico normativo retira a possibilidade de os país construirem uma interpretação sobre a doença de seu filho e acaba por submeter hierarquicamente a explicação da própria

\section{Referências}

1. Garcez EMF. Análise de fatores indicadores de disfunção miccional em crianças e adolescentes enuréticos [tese de doutorado]. Rio de Janeiro: Instituto Fernandes Figueira da Fundação Oswaldo Cruz; 2003.

2. Hagglof B, Andren O, Bergstrom E, Marklund L, Wendelius M. Self-esteem before and after treatment in children with nocturnal enuresis and urinary incontinence. Scand J Urol Nephrol 1996; 183: 79-82.

3. Moffat MEK, Kato C, Pless IB. Improvements in selfconcept after treatment of nocturnal enuresis: randomized controlled trial. J Pediatr 1987; 110: 647-52.

4. Warzak WJ. Psychological implications of nocturnal enuresis. Clin Pediatr 1993; 32: 38-40. Special edition.

5. Devlin JB, O'Cathalin C. Predicting treatment outcome in nocturnal enuresis. Arc Dis Child 1990; 65: 1158-61.

6. Kleinman A. Anthropology and psychiatry: the role of culture in cross-cultural research on illness. Br J Psychiatr 1987; 151: 447-54.

7. Good B. The heart of what's the matter: the semantics of illness in Iran. Cult Med Psychiatr 1977; 1: 25-58.

8. Helman CG. Cultura, saúde e doença. Porto Alegre: Artes Médicas; 1994.

9. Eisenberg L, Disease and illness: distinctions between professional and popular ideas of sickness. Cult Med Pscyhiatr 1977; 1: 9-23.

10. Adam P, Herzlich C. Sociologia da doença e da medicina. Bauru: Editora da Universidade do Sagrado Coração; 2001. família ao discurso médico científico, gerando uma "cópia" de explicação médica: a família repete o discurso médico, sem apropriar-se ou compreender o mesmo, repetindo então as práticas anteriormente criticadas sem haver internalizado a importância do tratamento, bem como as possibilidades que o mesmo proporciona. Podemos identificar famílias que conseguem operar com o diagnóstico médico, e com suas próprias interpretações sobre o processo de adoecimento vindo a elaborar com maior facilidade as explicações médicas e sofrendo com sentimentos de culpa e desvalorização de seu cuidado com a criança. É concebível ainda, direcionar estratégias de abordagem para pessoas que vivem com alguma doença, de uma maneira geral, e necessitem incorporar outras dimensões de entendimento do que seja viver com um distúrbio. Dessa forma, é possível que na sua prática de cuidados com a saúde o profissional seja menos normativo e informativo, e busque compreender o que seus pacientes possuem como recursos positivos para enfrentar seu mal-estar, instrumentalizando práticas mais dialógicas e comunicativas. $16-19$
11. Kleinman A. Patient and healers in the context of the culture. Califórnia: University of California Press. Berkeley; 1980. Apud: Helman CG. Cultura, saúde e doença. Porto Alegre: Artes Médicas; 1994.

12. Minayo MCS, Ciência, técnica e arte: o desafio da pesquisa social. In: Minayo MCS, Deslandes SF, Cruz Neto O, Gomes R. Pesquisa social: teoria, método e criatividade. Petrópolis: Vozes; 2001. p. 9-29.

13. Goldenberg M. A arte de pesquisar: como fazer pesquisa qualitativa em ciências sociais: Rio de Janeiro: Record; 1998.

14. D'Ancona CAL, Rodrigues NJN. Aplicações clínicas da urodinâmica. São Paulo: Atheneu; 1995.

15. Minayo MCS. O desafio do conhecimento: pesquisa qualitativa em saúde. São Paulo: Hucitec; 1994.

16. Rouco JJM. Sexualidade e mudanças de comportamentos: uma estratégia lúdica de prevenção da AIDS. In: Heilborn ML, organizador. Sexualidade: o olhar das ciências sociais. Rio de Janeiro: Jorge Zahar; 1999. p. 175-99.

17. Moreira MCN, Cunha CC. Repensando as práticas e dilemas no cotidiano de atenção à saúde de crianças e jovens vivendo com HIV/AIDS. Rev Saúde Debate 2003; 29: 73-92.

18. Moreira MCN, Souza WSA. Microssociologia de Erving Goffman e a análise relacional: um diálogo metodológico pela perspectiva das redes sociais na área de saúde. Teoria Soc 2002; 9: 38-61. 
19. Mitre R, Moreira MCN, Soares AHR, Junqueira MF, Maciel, MA, Oliveira MMQ, Mayrink MLS. Saúde e brincar: breaking barriers at a Brazilian hospital. Playrights [Stockholm] 2002; 24: 16-20.

Recebido em 25 de agosto de 2003

Versão final em 20 de junho de 2005

Aprovado em 26 de julho de 2005 